\title{
Calibrated NEXAFS spectra of common conjugated polymers
}

\author{
B. Watts, ${ }^{1, a)}$ S. Swaraj, ${ }^{1, b)}$ D. Nordlund, ${ }^{2, c)}$ J. Lüning, ${ }^{2, d)}$ and H. Ade ${ }^{1, e)}$ \\ ${ }^{1}$ North Carolina State University, Raleigh, North Carolina 27695, USA \\ ${ }^{2}$ Stanford Synchrotron Radiation Lightsource, Menlo Park, California 9402, USA
}

(Received 29 July 2010; accepted 1 October 2010; published online 11 January 2011)

\begin{abstract}
Near edge x-ray absorption fine structure (NEXAFS) spectroscopy has evolved into a powerful characterization tool for polymeric materials and is increasingly being used to elucidate composition and orientation in thin films of relevance to organic electronic devices. For accurate quantitative compositional analysis, insight into the electronic structure and the ability to assess molecular orientation, reliable reference spectra with known energy resolution and calibrated energy scale are required. We report a set of such NEXAFS spectra from 23 semiconducting polymers and some related materials that are frequently used in organic device research. () 2011 American Institute of Physics. [doi:10.1063/1.3506636]
\end{abstract}

\section{INTRODUCTION}

Near edge $x$-ray absorption fine structure (NEXAFS) spectroscopy is a powerful tool for identifying chemical functional groups in polymers and small molecules. ${ }^{1-4}$ In NEXAFS, photoabsorption creates excited states that can be described by electronic configurations in which a core electron is promoted to an energy level (orbital or band) that is empty in the ground state. ${ }^{4}$ It is thus inherently element sensitive as the binding energies of core electrons are specific for each element. In addition, due to a close relationship between molecular bonding and the energy and spatial distribution of the empty electronic levels, unique spectroscopic fingerprints can be assigned to specific chemical moieties. In general, a reference molecule used to identify functional groups through a finger-printing and a building block approach ${ }^{5-8}$ must be large enough to represent the spatial extent of the relevant electronic delocalization for the functional groups in a complex material. In semiconducting conjugated polymers, this building block approach is of more limited value as the molecular orbitals are extensively delocalized and might evolve more toward a one-dimensional band structure. In addition, intermolecular interactions including $\pi-\pi$ stacking can modify the electronic structure and hence the NEXAFS spectra in ordered materials. ${ }^{4,8,9}$ It is thus difficult to predict the NEXAFS spectra of conjugated polymers on the basis of their functional groups and backbone composition. Delocalization and intermolecular interactions also make theoretical calculations much more complex and time consuming.

\footnotetext{
a) Author to whom correspondence should be addressed. Electronic mail: benjamin.watts@psi.ch. Present address: Paul Scherrer Institute, Villigen CH-5232, Switzerland.

b) Present address: Synchrotron SOLEIL, L'Orme des Merisiers, SaintAubin-BP 48 F-91192 Gif-sur-Yvette cedex, France. Electronic mail: swaraj@synchrotron-soleil.fr.

${ }^{c}$ Electronic mail: dnordlund@stanford.edu.

d) Present address: Laboratoire de Chimie Physique-Matière et Rayonnement. Université Pierre et Marie Curie (Paris VI). 11, rue Pierre et Marie Curie, 75005 Paris, France. Electronic mail: Jan.Luning@ upmc.fr.

e) Electronic mail: hwade@ncsu.edu.
}

To facilitate the characterization of conjugated polymers using NEXAFS, as well as the characterization of structures composed of combinations of these materials using techniques that derive material contrast via NEXAFS, ${ }^{2}$ (e.g., scanning transmission x-ray microscopy, ${ }^{10-18}$ resonant scattering, ${ }^{19-22}$ and resonant reflectivity ${ }^{23-26}$ ) we present a calibrated library of C1s NEXAFS spectra of some frequently utilized conjugated polymers. We enhance the utility of the presented polymer spectra by acquisition on a common energy scale and with high energy resolution. We have also exercised care to avoid acquisition artifacts and to normalize these spectra as best as possible to facilitate an accurate conversion to absorption cross-sections or optical constants. The latter are critically important for characterization with resonant scattering and resonant reflectivity. ${ }^{19-26}$ A relatively detailed primer about the NEXAFS spectroscopy of many common polymers has been previously provided by Dhez et al. $^{3}$ and Kikuma and Tonner, ${ }^{27}$ complemented by a series of NEXAFS spectra illuminating the evolutionary trend of the spectral signature of carbonyl functional groups as the nearest neighbor environment is changed progressively and systematically from a ketone to a carbonate group. ${ }^{4}$ Complementary work on small molecules for use in solar cells was provided by Cook et al. ${ }^{28}$ while Hitchcock and Mancini ${ }^{29}$ maintain a database of spectra of a broad range of gas phase molecules. None of these systematic catalogs of reference spectra have involved conjugated polymers. Conjugated polymers were primarily investigated with NEXAFS as part of specific studies, most often investigating the orientation or composition near an interface ${ }^{9,30-43}$ or as a tool to quantify bulk morphology in blends related to photovoltaic devices. ${ }^{10-16,18}$ Our primary goal with this manuscript is the presentation of accurately calibrated, high energy resolution, high signal/noise NEXAFS spectra of common conjugated polymers, and to provide spectral trends in some conjugated polymer families. A subset of the spectra will be discussed in detail in additional publications. The focus here is on reference spectroscopy including a detailed discussion of the energy calibration procedure. For details on the general principles of NEXAFS spectroscopy and microscopy, the reader is referred 
to the literature. ${ }^{1,2,44}$ Tabular versions of the spectra are available at http://carbon.physics.ncsu.edu/polymer-spectra/.

\section{EXPERIMENT}

\section{A. Materials}

Materials were obtained and used without further processing from the suppliers listed below (refer to Tables I-V for full names and chemical structures corresponding to the abbreviations used here). MDMO-PPV, MEH-PPV, MEH-PP, DOO-PP, PFO, F8BT, F8-co-BT, PFB, TB, TFB, PMHT, PFT2, PDQT, P3HT, PCBM-C 61 (purity >99.5\%), and PCBM- $\mathrm{C}_{71}$ (purity $>99.0 \%$ ) were purchased from American Dye Source, Inc.; DEH-PPV, DEP-PPV, DDDO-PPV, DOO-PPV, DBO-PPV, DTE-PPV, DDE-PPV, and DE-PPV were obtained from the Segalman research group of the University of California, Berkeley; PFB, F8BT, and F8TBT were obtained from Cambridge Display Technologies Ltd.; Baytron ${ }^{\circledR}$ P (PEDOT:PSS, 1:2.5 by weight) and Al4083 (PEDOT:PSS, 1:6 by weight) were purchased from H.C. Starck GmbH; PCBM-C 61 (purity >99\%) was purchased from Nano-C; and PSS was purchased from Sigma-Aldrich Co.; P3HT was purchased from Merck KGaA. Identical spectra were observed in the cases where materials were obtained from multiple sources (i.e., MEH-PPV, PFB, F8BT, P3HT, and PCBM-C 61 ).

\section{B. Methods}

Thin films were spin cast from chlorobenzene (except for PEDOT:PSS and PSS, which are water soluble) at $3 \mathrm{krpm}$, in a nitrogen environment, onto doped $\mathrm{Si}$ substrates and baked in vacuum at $140^{\circ} \mathrm{C}$ for $1 \mathrm{~h}$ in order to remove any residual solvent. Care was exercised to ensure that smooth, continuous films were formed and that oxygen exposure was minimized.

Total electron yield (TEY) NEXAFS spectra were recorded at $20^{\circ}$ (grazing), $50^{\circ}$, and $90^{\circ}$ (normal) angles of x-ray incidence at beamline 10-1 at the Stanford Synchrotron Radiation Lightsource, Menlo Park, California, with an energy resolution $(E / \Delta E)$ greater than 6000 and linear polarization of approximately $80 \%$. The gold mesh flux monitor and sample drain currents were simultaneously measured with Keithley 428 current amplifiers and the resulting spectra normalized via the Clean Monitor method. ${ }^{44}$

Cleanliness of the flux monitor was ensured by evaporating a fresh layer of gold onto the gold wire mesh from which the incident photon flux was measured via the drain current. A titanium oxide film (strongly absorbing photons with energies above the Ti L-edge at $454 \mathrm{eV}$ and $\mathrm{O} \mathrm{K}$-edge at 530 $\mathrm{eV}$ ) was employed to suppress second order light passed by the monochromator. Absolute energy calibration of the data was performed via measurements of the highly oriented pyrolytic graphite (HOPG) exciton peak at $291.65 \mathrm{eV}^{45}$ Since the monochromator calibration was known to drift slightly over time, relative energy calibrations were made via a simultaneous NEXAFS experiment on a reference sample (consisting of various transition metal elements and significant carbon) that intercepted the edge of the beam just upstream of the experimental chamber.
Initial experience with TEY measurements of conjugated polymers has shown that if the polymer film has been exposed to oxygen prior to measurement, then the drain current signal will typically display a gradual decrease in magnitude without any change in the underlying spectrum. This effect is due to photo-oxidation causing a gradual increase in the electrical resistance of the polymer material through a reduced conjugation length ${ }^{46}$ or changes in the work function that change the electron yield. The underlying spectrum remains unchanged as the majority of the material probed within the electron escape depth remains chemically unmodified. However, while the underlying spectrum is not significantly affected by photo-oxidation during NEXAFS measurements, the decrease in signal current interferes with normalization of the data and is difficult to properly account for. Therefore, in these experiments the effects of photo-oxidation were avoided in two ways: First, oxygen exposure of the sample films was avoided via processing and storage under a nitrogen atmosphere. Second, repeat scans were recorded and compared to ensure that the observed spectral signals were identical and hence, photo-oxidation was not occurring. This prudence is particularly important in order to achieve accurate scattering factors (see below).

\section{Data processing}

The spectra were photon flux normalized using the Clean Monitor method described by Watts et al. ${ }^{44}$ Briefly, the signals were energy aligned to account for drift of the monochromator and then the sample signal was divided by the flux monitor signal (modified to account for the absorption spectrum of gold). For display in this article, the spectra were normalized and converted to oscillator strength by scaling the observed spectra to the weighted sum of the elemental $\mathrm{x}$-ray absorption coefficients ${ }^{47}$ corresponding to the molecular repeat unit, divided by the number of carbon atoms per repeat unit.

Resonance positions were determined by manually assigning, then least-squares fitting, a set of symmetric and asymmetric Gaussian peaks, and an error function with exponentially decaying tail for the step edge. The detailed spectral assignment of NEXAFS resonances is a complex task, especially so with the spectra presented in this work that each display many closely convoluted resonances due to complicated molecular structures and delocalized electronic structure. Since the focus here is to provide reliable reference spectra and not a detailed interpretation and detailed spectroscopic assignments, the resonance positions given here are intended only to aid the reader in observing the sometimes subtle differences in the spectra of materials with similar functional groups and chemical structure.

The data provided in this database are intended to aid in the design and analysis of $\mathrm{x}$-ray experiments to investigate polymer systems. As such, the parameters of greatest interest are the photoabsorption cross-section, $\sigma$, (which is proportional to the signal measured in a NEXAFS experiment) and the absorptive and dispersive parts of the refractive index, $\beta$ and $\delta$. However, $\beta$ and $\delta$ depend on the density of the material, which is not precisely known for many of the 
TABLE I. Structures and names of some alkyloxy phenylenevinylene polymer materials.

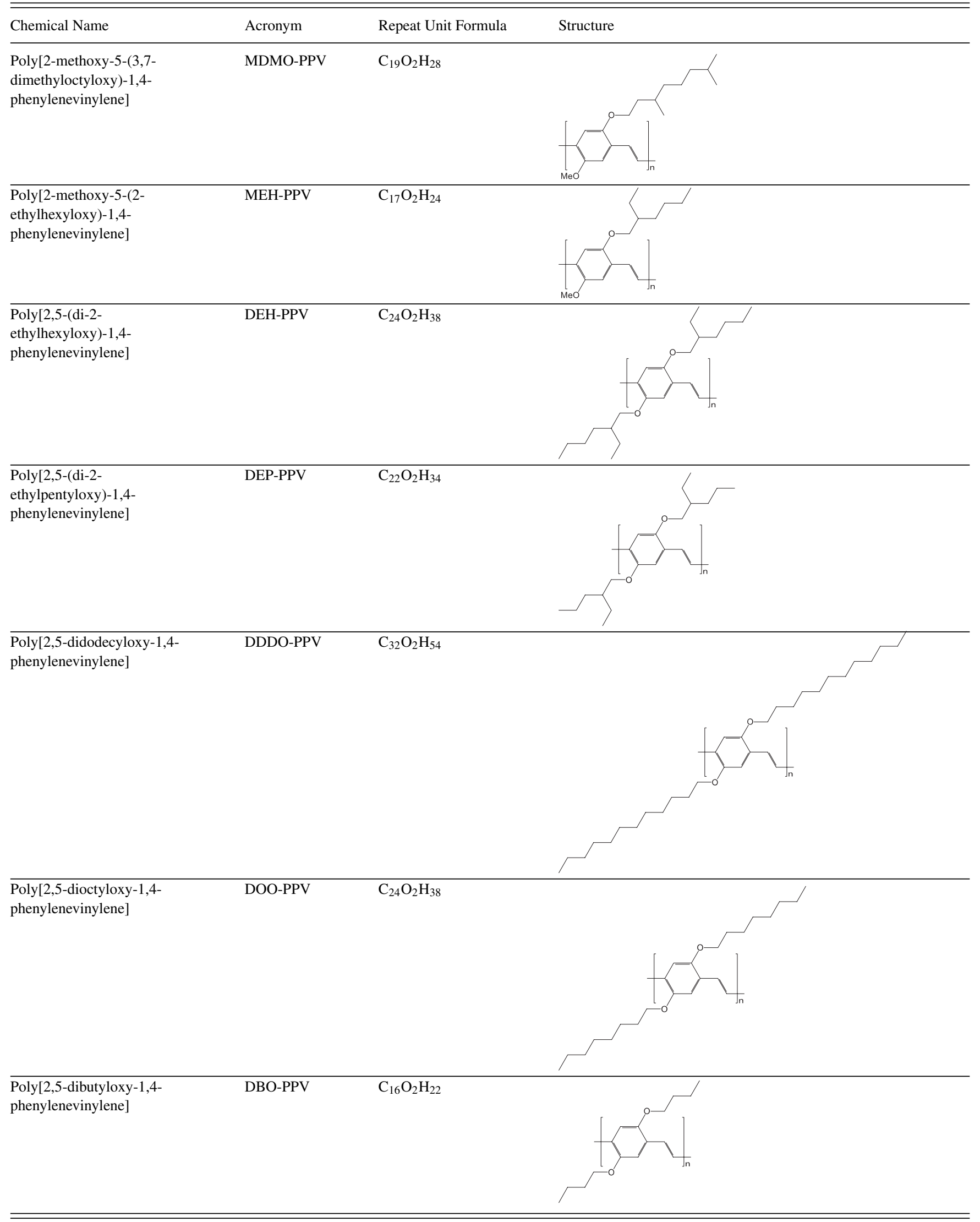


TABLE II. Structures and names of some phenylene and phenylenevinylene polymer materials.

\begin{tabular}{|c|c|c|c|}
\hline Chemical Name & Acronym & $\begin{array}{l}\text { Repeat Unit } \\
\text { Formula }\end{array}$ & Structure \\
\hline $\begin{array}{l}\text { Poly[2-methoxy-5-(2- } \\
\text { ethylhexyloxy)-1,4-phenylene] }\end{array}$ & MEH-PP & $\mathrm{C}_{15} \mathrm{O}_{2} \mathrm{H}_{22}$ & \\
\hline $\begin{array}{l}\text { Poly[2,5-dioctyloxy-1,4- } \\
\text { phenylene] }\end{array}$ & DOO-PP & $\mathrm{C}_{22} \mathrm{O}_{2} \mathrm{H}_{36}$ & \\
\hline $\begin{array}{l}\text { Poly[2,5-di-\{[2-(2- } \\
\text { ethoxyethoxy)ethoxy]methoxy }\} \text { - } \\
\text { 1,4-phenylenevinylene] }\end{array}$ & DTE-PPV & $\mathrm{C}_{22} \mathrm{O}_{8} \mathrm{H}_{34}$ & \\
\hline $\begin{array}{l}\text { Poly[2,5-di-\{(2- } \\
\text { ethoxyethoxy)methoxy }\}-1,4- \\
\text { phenylenevinylene] }\end{array}$ & DDE-PPV & $\mathrm{C}_{18} \mathrm{O}_{6} \mathrm{H}_{26}$ & \\
\hline $\begin{array}{l}\text { Poly[2,5-di-(ethoxymethoxy)- } \\
\text { 1,4-phenylenevinylene] }\end{array}$ & DE-PPV & $\mathrm{C}_{14} \mathrm{O}_{4} \mathrm{H}_{18}$ & \\
\hline
\end{tabular}

materials presented here. We have therefore chosen to present the data in the form of scattering factors, analogous to the atomic scattering factors described by Henke et al. ${ }^{47,48}$ These scattering factors, $f$, are wavelength dependent complex values $\left(f(\lambda)=f_{1}(\lambda)+i f_{2}(\lambda)\right)$ that describe the small angle, forward scattering of photons of wavelength $\lambda$. The scattering factors are defined with respect to the refractive index, $R I$, of a material composed of $q$ different types of atoms as

$$
\begin{aligned}
R I(\lambda) & =1-\delta(\lambda)-i \beta(\lambda) \\
& =1-\frac{1}{2 \pi} r_{0} \lambda^{2} \sum_{q} N_{q} f_{q}(\lambda),
\end{aligned}
$$

where $r_{0}$ is the classical electron radius, $N_{q}$ is the number density of atoms of type $q$ per unit volume, and $f_{q}(\lambda)$ is the complex atomic scattering factor for a $q$-type atom as a function of photon wavelength. While this approach works well for photon wavelengths far from any absorption edge of the sample material, where interatomic interactions are not significant, we would like to use the scattering factor approach to describe the near-edge spectral features of organic materials. Thus some reinterpretation is required.

Since near-edge resonance features depend strongly on the interactions between atoms, the basic particles, $q$, in Eq. (1) must involve polyatomic moieties. In the case of organic materials, the natural choice for such a "particle" is the molecule, or in the case of polymer materials, as we are chiefly concerned here, the repeat unit. Equation (1) could therefore be restated as 
TABLE III. Structures and names of some fluorenyl polymer materials.

\begin{tabular}{|c|c|c|c|}
\hline Chemical Name & Acronym & Repeat Unit Formula & Structure \\
\hline $\begin{array}{l}\text { Poly[4,4'-(N-(4-sec- } \\
\text { butylphenyl))diphenylamine] }\end{array}$ & TB & $\mathrm{C}_{22} \mathrm{NH}_{21}$ & \\
\hline $\begin{array}{l}\text { Poly[(9,9-dioctylfluorenyl- } \\
\text { 2,7-diyl)-co-( } 4,4^{\prime}-(\mathrm{N}-(4-\mathrm{sec}- \\
\text { butylphenyl }) \text { diphenylamine })]\end{array}$ & TFB & $\mathrm{C}_{51} \mathrm{NH}_{61}$ & \\
\hline 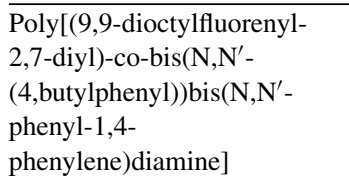 & PFB & $\mathrm{C}_{67} \mathrm{~N}_{2} \mathrm{H}_{78}$ & \\
\hline $\begin{array}{l}\text { Poly(9,9-dioctylfluorenyl- } \\
\text { 2,7-diyl) }\end{array}$ & PFO & $\mathrm{C}_{29} \mathrm{H}_{40}$ & \\
\hline $\begin{array}{l}\text { Poly[(9,9-dioctylfluorenyl- } \\
2,7 \text {-diyl)-co-(1,4-benzo- } \\
\left.\left.\left\{2,1^{\prime}, 3\right\} \text {-thiadiazole }\right)\right]\end{array}$ & F8coBT & $\mathrm{C}_{26.7} \mathrm{~N}_{0.2} \mathrm{~S}_{0.1} \mathrm{H}_{36.2}$ & \\
\hline $\begin{array}{l}\text { Poly[(9,9-dioctylfluorenyl- } \\
\text { 2,7-diyl)-co-(1,4-benzo- } \\
\left.\left.\left\{2,1^{\prime}, 3\right\} \text {-thiadiazole }\right)\right]\end{array}$ & F8BT & $\mathrm{C}_{35} \mathrm{~N}_{2} \mathrm{SH}_{42}$ & \\
\hline
\end{tabular}

$$
\begin{aligned}
R I(\lambda) & =1-\delta(\lambda)-i \beta(\lambda) \\
& =1-\frac{1}{2 \pi} r_{0} \lambda^{2} \sum_{s} N_{s} f_{s}^{\prime}(\lambda),
\end{aligned}
$$

where $N_{s}$ and $f_{s}^{\prime}$ are the number-density and scattering factors for a molecule (or polymer repeat unit) of type $s$. At wavelengths far from the absorption edges, the molecular scattering factor, $f^{\prime}$, in Eq. (2) is related to the atomic scattering factors, $f$, described in Eq. (1) via simple addition of the atomic scattering factors in proportion to the molecular stoichiometry:

$$
f_{s}^{\prime}(\lambda)=\sum_{q} N_{q} f_{q}(\lambda) .
$$

And since now, $f^{\prime}$, describes the photon scattering of a polyatomic entity, the corresponding near-edge structure can be consistently incorporated into the scattering factor concept. Therefore, using Eqs. (2) and (3), one can describe both the absorptive and dispersive near-edge structures of organic materials in a way that externalize knowledge of (and hence errors in) the material density.
Another parameter of interest, the atomic photoabsorption cross-section, is related by Henke et al. to the scattering factors by

$$
\sigma_{a}(\lambda)=2 r_{0} \lambda f_{2}(\lambda)
$$

where $\sigma_{a}$ is the atomic photoabsorption cross-section and $f_{2}$ is the imaginary part of the atomic scattering factor. Again, using Eq. (3) we can easily extend this concept to define a molecular (or repeat unit) photoabsorption cross-section, $\sigma_{m}$,

$$
\sigma_{m}(\lambda)=2 r_{0} \lambda f_{2}^{\prime}(\lambda) .
$$

In order to produce the molecular scattering factor data for this database, we first used Eq. (3) to calculate the element-derived values based on the molecular formulae, i.e., elemental ratios. Then, the experimental NEXAFS data that contain the electronic structure specific information were converted to the molecular scattering factor component $f_{2}^{\prime}$ using Eq. (5) and were spliced into the calculated element ratio based values. The imaginary part of the scattering factor thus produced is now accurate both in the region of the $\mathrm{C}$ K-edge and far from it. While inaccuracies that reflect molecular bonding remain in the vicinity of the $\mathrm{O}, \mathrm{N}$, and 
TABLE IV. Structuress and names of some thiophene polymer materials.

\begin{tabular}{|c|c|c|c|}
\hline Chemical Name & Acronym & Repeat Unit Formula & Structure \\
\hline $\begin{array}{l}\text { Poly[(9,9-dioctylfluorenyl-2,7-diyl)- } \\
\text { alt-(4,7-bis(3-hexylthiophen-5-yl)- } \\
\text { 2,1,3-benzothiadiazole)-2 } 2^{\prime}, 2^{\prime \prime}- \\
\text { diyl] }\end{array}$ & F8TBT & $\mathrm{C}_{55} \mathrm{~N}_{2} \mathrm{~S}_{3} \mathrm{H}_{70}$ & \\
\hline $\begin{array}{l}\text { Poly[(9,9-dioctylfluorenyl-2,7-diyl)- } \\
\text { co-(bithiophene)] }\end{array}$ & PFT2 & $\mathrm{C}_{37} \mathrm{~S}_{2} \mathrm{H}_{44}$ & \\
\hline $\begin{array}{l}\text { Regioregular Poly(3-methyl-4- } \\
\text { hexylthiophene-2,5-diyl) }\end{array}$ & PMHT & $\mathrm{C}_{11} \mathrm{SH}_{16}$ & \\
\hline $\begin{array}{l}\text { Poly }\left(3,3^{\prime \prime \prime} \text {-didodecyl quarter }\right. \\
\text { thiophene })\end{array}$ & PDQT & $\mathrm{C}_{40} \mathrm{~S}_{4} \mathrm{H}_{56}$ & \\
\hline $\begin{array}{l}\text { Regioregular } \\
\text { Poly(3-hexylthiophene-2,5-diyl) }\end{array}$ & P3HT & $\mathrm{C}_{10} \mathrm{SH}_{14}$ & \\
\hline
\end{tabular}

$\mathrm{S}$ edges for materials containing these elements, they do not significantly affect the use of the scattering factors at the C K-edge, which is the primary aim of this work. Additionally, further experimental data at other absorption edges could later be integrated into the molecular scattering factors in order to further refine them. Finally, the real part of the molecular scattering factor was recalculated from the more accurate imaginary part via the Kramer-Kronig relations. ${ }^{47,49,50}$ (Similarly to the atomic scattering factor files, ${ }^{47,48} f_{1}$ values at photon energies below $29 \mathrm{eV}$ are set to -9999 in order to reflect the fact that the calculated $f_{1}$ values are not reliable in this photon energy range.) These molecular scattering factors can be easily transformed into useful values for the optical constants and cross-section via Eqs. (2) and (5) and are available at http://carbon.physics.ncsu.edu/polymer-spectra/.

Spectra were recorded (and are made available) at multiple angles of $\mathrm{x}$-ray incidence in order to demonstrate anisotropy in near-edge resonances. However, the spectral anisotropy follows from the molecular alignment and orientation of the sample material, which is known to depend on the processing conditions (e.g., annealing ${ }^{30}$ ) and so cannot be relied upon to be exactly reproducible. So while the energy and spectral assignment of the anisotropic resonances will remain constant between samples, the sense and magnitude of the anisotropy will likely be observed to vary somewhat.

\section{RESULTS AND DISCUSSION}

NEXAFS spectra of materials with a range of functional groups exhibit spectral features that can be classified into four broad categories. The lowest energy features near 285 $\mathrm{eV}$ typically correspond to $\mathrm{C} 1 \mathrm{~s}(\mathrm{C}=\mathrm{C}) \rightarrow \pi_{\mathrm{C}=\mathrm{C}}^{*}$ transitions associated with aromatics and unsubstituted unsaturation. Features in the 285.5-287 eV range often correspond to $\mathrm{C} 1 \mathrm{~s}(\mathrm{C}-\mathrm{R}) \rightarrow \pi^{*}$ transitions of substituted unsaturated carbon atoms. $\mathrm{C} 1 \mathrm{~s}(\mathrm{C}-\mathrm{H}) \rightarrow \sigma_{\mathrm{C}-\mathrm{H}}^{*}$ resonances have features between 287 and $288.5 \mathrm{eV}$ and $\mathrm{C} 1 \mathrm{~s}(\mathrm{C}-\mathrm{C}) \rightarrow \sigma_{\mathrm{C}-\mathrm{C}}^{*}$ features are above $293 \mathrm{eV}$.

Figure 1 displays the spectra of the various phenylenevinylene polymers listed in Table I. Five C1s $\rightarrow \pi^{*}$ resonance peaks can be seen near $285 \mathrm{eV}$ and show little variation within this set of spectra, while greater differences can be seen in the $\mathrm{C} 1 \mathrm{~s}(\mathrm{C}-\mathrm{H}) \rightarrow \sigma_{\mathrm{C}-\mathrm{H}}^{*}$ resonances near 287.5-288 eV. This is consistent with the molecu- 
TABLE V. Structures and names of some materials often utilized in polymer electronic devices.

\begin{tabular}{|c|c|c|c|}
\hline Chemical Name & Acronym & $\begin{array}{l}\text { Repeat Unit } \\
\text { Formula }\end{array}$ & Structure \\
\hline $\begin{array}{l}{[6,6] \text {-Phenyl C61-butyric }} \\
\text { acid methyl ester }\end{array}$ & PCBM-C 61 & $\mathrm{C}_{72} \mathrm{O}_{2} \mathrm{H}_{14}$ & \\
\hline $\begin{array}{l}{[6,6] \text {-Phenyl C71-butyric }} \\
\text { acid methyl ester }\end{array}$ & $\mathrm{PCBM}^{-\mathrm{C}_{71}}$ & $\mathrm{C}_{82} \mathrm{O}_{2} \mathrm{H}_{14}$ & \\
\hline $\begin{array}{l}\text { Poly(3,4- } \\
\text { ethylenedioxythiophene) } \\
\text { and } \\
\text { Poly(styrenesulfonate) } \\
\text { Blend }\end{array}$ & PEDOT:PSS & $\begin{array}{c}\text { Baytron } \mathrm{P}: \\
\mathrm{C}_{7.3} \mathrm{SO}_{2.7} \mathrm{H}_{6}, \\
\mathrm{Al} 4083: \\
\mathrm{C}_{7.6} \mathrm{SO}_{2.8} \mathrm{H}_{6.5}\end{array}$ & \\
\hline Poly(styrenesulfonate) & PSS & $\mathrm{C}_{8} \mathrm{SO}_{3} \mathrm{H}_{7}$ & \\
\hline
\end{tabular}

lar structure of the materials; the $\mathrm{C} 1 \mathrm{~s} \rightarrow \pi^{*}$ resonances are derived from the conjugated phenylenevinylene backbone of the polymers and is identical throughout the set, while the solubulizing alkyloxy side chains that vary between the materials are apparent in the variation of the $\mathrm{C} 1 \mathrm{~s}(\mathrm{C}-\mathrm{H})$ $\rightarrow \sigma_{\mathrm{C}-\mathrm{H}}^{*}$ resonances. Molecular alignment effects, angle of $\mathrm{X}$-ray incidence dependent differences in oscillator strength, are observable only in the $\mathrm{C} 1 \mathrm{~s}(\mathrm{C}-\mathrm{H}) \rightarrow \sigma_{\mathrm{C}-\mathrm{H}}^{*}$ resonances of DDDO-PPV and DOO-PPV, which have the longest alkyl side chains and are therefore the most ordered. The NEXAFS of alkyl or alkyloxy based materials and their crystallization and orientation effects is well studied and of less interest here. ${ }^{4-6,51,52}$

It should be noted that none of the spectra shown in Fig. 1, nor any of the other spectra reported in this work, display any sharp resonance features on the order of the core hole limited width of $\sim 100 \mathrm{meV}$, despite the fact that the beamline has an energy resolution $(E / \Delta E)$ greater than 6000 (corresponding to $50 \mathrm{meV}$ at the $\mathrm{C}$ K-edge). Urquhart et al. ${ }^{53}$ observed fine structure in the NEXAFS spectra of polystyrene and demonstrated that it is due to a significant vibronic contribution to the shape and structure of the $\mathrm{C} 1 \mathrm{~s}(\mathrm{C}-\mathrm{H}) \rightarrow \pi_{\mathrm{C}=\mathrm{C}}^{*}$ transition. A reasonable explanation for the lack of fine structure in the spectra shown here is that the extensive delocalization of the molecular orbitals of these conjugated polymer materials exhibit the electronic structure of a broader band structure. This should be particularly pronounced for amorphous polymers, which show more varied local electronic structure than ordered, i.e., crystalline, polymers, or mixtures of ordered and disordered materials.
Greater differences are observed between the spectra of the phenylene polymers MEH-PP and DOO-PP, and their phenylenevinylene counterparts, MEH-PPV and DOO-PPV, shown in Fig. 2. Here, one can see that the $\mathrm{C} 1 \mathrm{~s} \rightarrow \pi^{*}$ resonances of the phenylenevinylene polymers involve many separate peaks, reaching to lower energies than that of the phenylene polymers.

The spectra of the final set of PPV materials, containing extra ether oxygen atoms in the side chains, are shown in Fig. 3. While these spectra show strong similarity to those of their alkyl side-chain PPV counterparts in the $\mathrm{C} 1 \mathrm{~s} \rightarrow \pi *$ resonances (Fig. 1) below $287 \mathrm{eV}$, they show strong differences in the energy range from 287 to $290 \mathrm{eV}$. Similarity in the C1s $\rightarrow \pi^{*}$ resonances is consistent with the presence of the same PPV backbone of the molecules, since only the backbone structure contains the $\mathrm{C}=\mathrm{C}$ double bonds required for $\pi$-type bonding. In the same manner, the observed spectral differences in the 287-290 eV energy region between the PPV spectra of Figs. 1 and 3 are consistent with the chemical differences of the side chains. The $\mathrm{C} 1 \mathrm{~s}(\mathrm{C}-\mathrm{O}) \rightarrow \sigma_{\mathrm{C}-\mathrm{H}}^{*}$ resonances are shifted to higher energies, i.e., 289-290 eV, relative to $\mathrm{C} 1 \mathrm{~s}(\mathrm{C}-\mathrm{H}) \rightarrow \sigma_{\mathrm{C}-\mathrm{H}}^{*}$ transitions. This is similar to energy shifts observed for poly(ethylene oxide), poly(methylene oxide), and a number of polyols relative to polyethylene or polypropylene. . $^{3,54}$

Figure 4 shows the spectra of the group of fluorenylbased polymers (with the exception of TB, which does not include the fluorenyl structure but is included in this grouping for comparison to TFB) listed in Table III. The spectrum of PFO, consisting purely of the dioctylfluorenyl structure, is dominated by a strong fluorenyl 

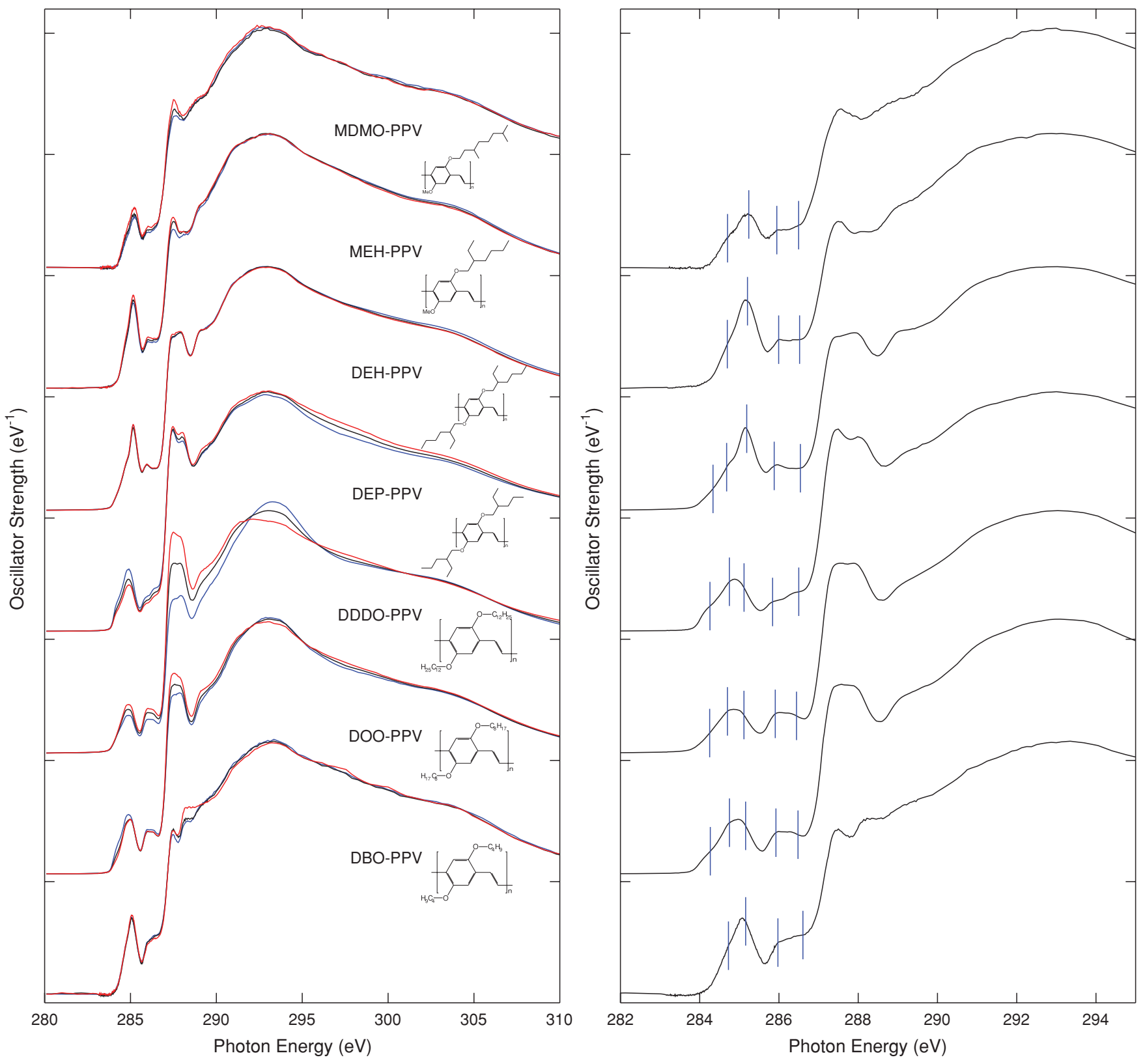

\begin{tabular}{cccccccc}
\hline \multicolumn{8}{c}{ Energy (eV) } \\
\hline$\#$ & $\begin{array}{c}\text { MDMO- } \\
\text { PPV }\end{array}$ & $\begin{array}{c}\text { MEH- } \\
\text { PPV }\end{array}$ & $\begin{array}{c}\text { DEH- } \\
\text { PPV }\end{array}$ & $\begin{array}{c}\text { DEP- } \\
\text { PPV }\end{array}$ & $\begin{array}{c}\text { DDDO- } \\
\text { PPV }\end{array}$ & $\begin{array}{c}\text { DOO- } \\
\text { PPV }\end{array}$ & $\begin{array}{c}\text { DBO- } \\
\text { PPV }\end{array}$ \\
\hline 1 & & & 284.34 & 284.26 & 284.25 & 284.27 & \\
2 & 284.70 & 284.70 & 284.68 & 284.75 & 284.70 & 284.75 & 284.73 \\
3 & 285.24 & 285.21 & 285.19 & 285.12 & 285.12 & 285.16 & 285.16 \\
4 & 285.95 & 285.99 & 285.88 & 285.84 & 285.91 & 285.92 & 285.97 \\
5 & 286.50 & 286.52 & 286.54 & 286.50 & 286.44 & 286.48 & 286.61 \\
\hline
\end{tabular}

FIG. 1. (left) C 1s NEXAFS spectra of MDMO-PPV, MEH-PPV, DEH-PPV, DEP-PPV, DDDO-PPV, DOO-PPV, and DBO-PPV (labels for polymers refer to Table I) at $20^{\circ}$ (blue), $50^{\circ}$ (black), and $90^{\circ}$ (normal, red) x-ray incidence. (right) Expanded low energy regions of the same spectra with vertical lines marking the fitted resonance positions.

$\mathrm{C} 1 \mathrm{~s} \rightarrow \pi^{*}$ resonance at $285.01 \mathrm{eV}$ and also shows significant $\mathrm{C} 1 \mathrm{~s}(\mathrm{C}-\mathrm{H}) \rightarrow \sigma_{\mathrm{C}-\mathrm{H}}^{*}$ resonances due to the saturated dioctyloxy side chains. PFO also demonstrates alignment effects with the variation in $\mathrm{C} 1 \mathrm{~s} \rightarrow \pi^{*}$ resonance intensity indicating that the ring structures of the surface fluorenyl groups tend to align parallel to the film surface. Interestingly, TB, with its different arrangement of aromatic rings, has a very similar spectrum to that of PFO. The greatest difference between the spectra of TB and PFO is an extra peak near $286.5 \mathrm{eV}$, due to the influence of the nitrogen atoms and thus allowing us to assign the peak as a $\mathrm{C} 1 \mathrm{~s}(\mathrm{C}-\mathrm{N}) \rightarrow \pi^{*}$ transition. This is similar to any substituted aromatics, such as substituted polystyrene or the aromatic groups in polyurea, polyurethane, or polycarbonate. ${ }^{2,54}$ The PFO also has a stronger set of $\mathrm{C} 1 \mathrm{~s}$ 

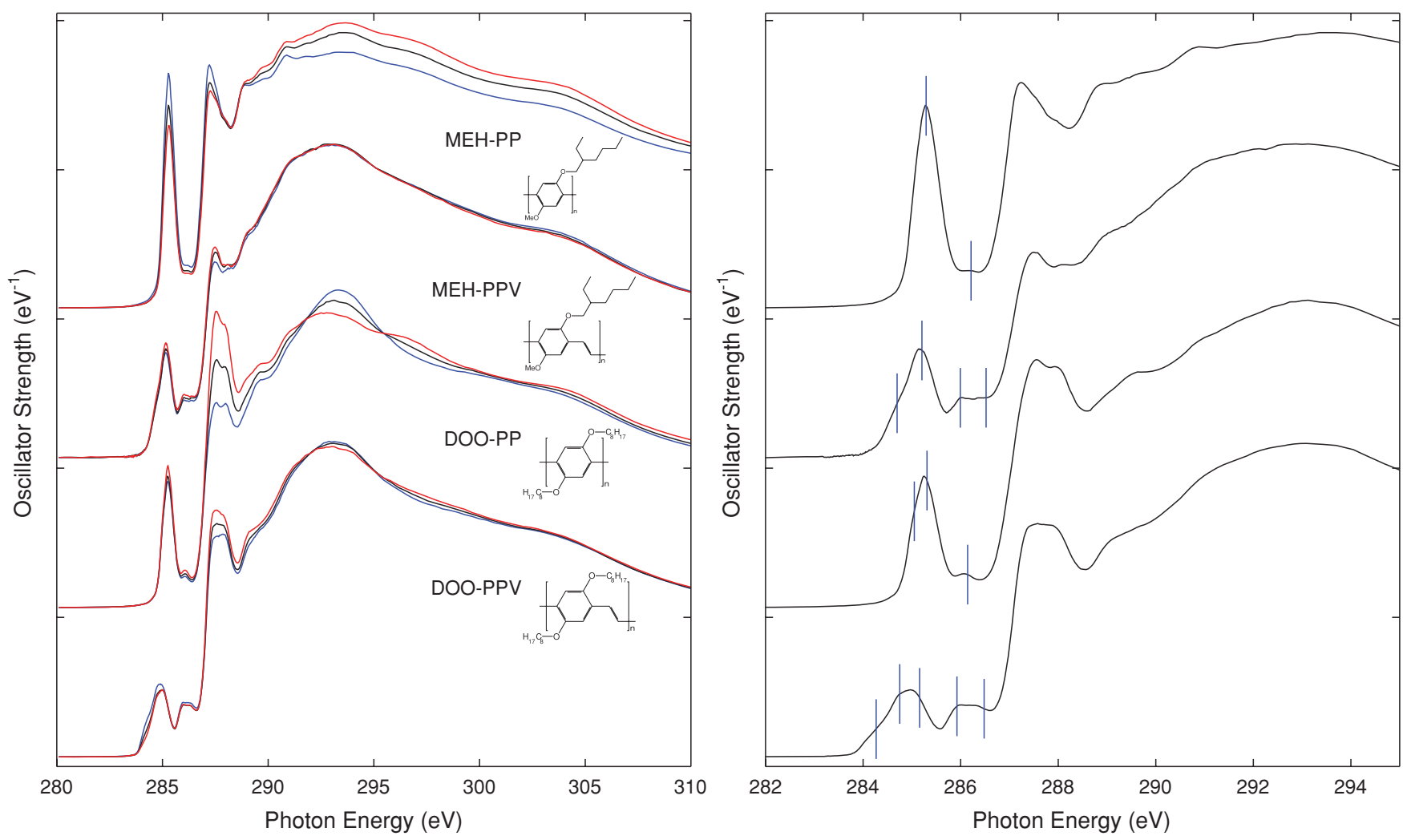

\begin{tabular}{ccccc}
\hline \multicolumn{5}{c}{ Energy (eV) } \\
\hline$\#$ & MEH-PP & MEH-PPV & DOO-PP & DOO-PPV \\
\hline 1 & & & & 284.27 \\
2 & & 284.70 & 285.05 & 284.75 \\
3 & 285.29 & 285.21 & 285.31 & 285.16 \\
4 & 286.21 & 285.99 & 286.14 & 285.92 \\
5 & & 286.52 & & 286.48 \\
\hline
\end{tabular}

FIG. 2. (left) C 1s NEXAFS spectra of MEH-PP, MEH-PPV, DOO-PP, and DOO-PPV (labels for polymers refer to Tables I and II) at $20^{\circ}$ (blue), $50^{\circ}$ (black), and $90^{\circ}$ (normal, red) x-ray incidence. (right) Expanded low energy regions of the same spectra with vertical lines marking the fitted resonance positions.

$(\mathrm{C}-\mathrm{H}) \rightarrow \sigma_{\mathrm{C}-\mathrm{H}}^{*}$ features, in line with the greater proportion of aliphatic carbon in PFO compared to TB. Now, TFB is a copolymer of the dioctyl-fluorenyl and triphenyl-amine structures present in the homopolymers PFO and TB. In line with the building block scheme, the NEXAFS spectrum of TFB is very close to a linear combination of the PFO and TB spectra (not shown here explicitly), signifying that no special interactions occur between the dioctyl-fluorenyl and triphenyl-amine structures that make up the TFB polymer backbone. Although not an exact match, we can also make a similar comparison with PFB, whose spectrum is close to a linear combination of the PFO and TB spectra, with a larger proportion of the triphenyl-amine structure than TFB. Again, this indicates that significant electronic interaction between the structures along the PFB backbone is unlikely.

In contrast, the spectrum of F8BT is considerably different from that of PFO, despite sharing the dioctyl-fluorenyl structure. This is directly apparent from the spectra without the need for a numerical simulation: The lowest energy features are clearly split in F8BT, but not so in PFO. More importantly, F8BT has a feature or shoulder lower in energy than PFO. This can only be explained by an interaction between the fluorenyl and benzothiadiazole structures of the F8BT backbone that results in significant splitting and shifting of the $\mathrm{C} 1 \mathrm{~s} \rightarrow \pi^{*}$ resonances. Another interesting feature of the set of fluorenyl-based polymer spectra is that even though F8BT and F8-co-BT share with PFO the spectral variations that demonstrate partial molecular alignment, TB, TFB, and PFB show no evidence of molecular alignment effects in their spectra.

Figure 5 shows spectra of the group of thiophene-based polymers listed in Table IV. One shared feature of these spectra is the relatively high pre-edge intensity, due to the presence of a significant proportion of sulfur, which can be seen at the extreme left of Fig. 5 via the large distance of the trace above the tick marks, which represent the zero for each spectrum. However, sulfur has little other easily assignable impact on the form of the spectrum at the $\mathrm{C}$ $\mathrm{K}$-edge, even though heteroatoms in aromatic structures are known to cause a splitting of the low energy $\pi^{*}$ peak (see, for example, the spectral difference between polystyrene and poly(2-vinyl pyridine $)^{2}$ ).

The most basic and most common of the thiophene polymers is $\mathrm{P} 3 \mathrm{HT}$, which consists of a chain of thiophene 

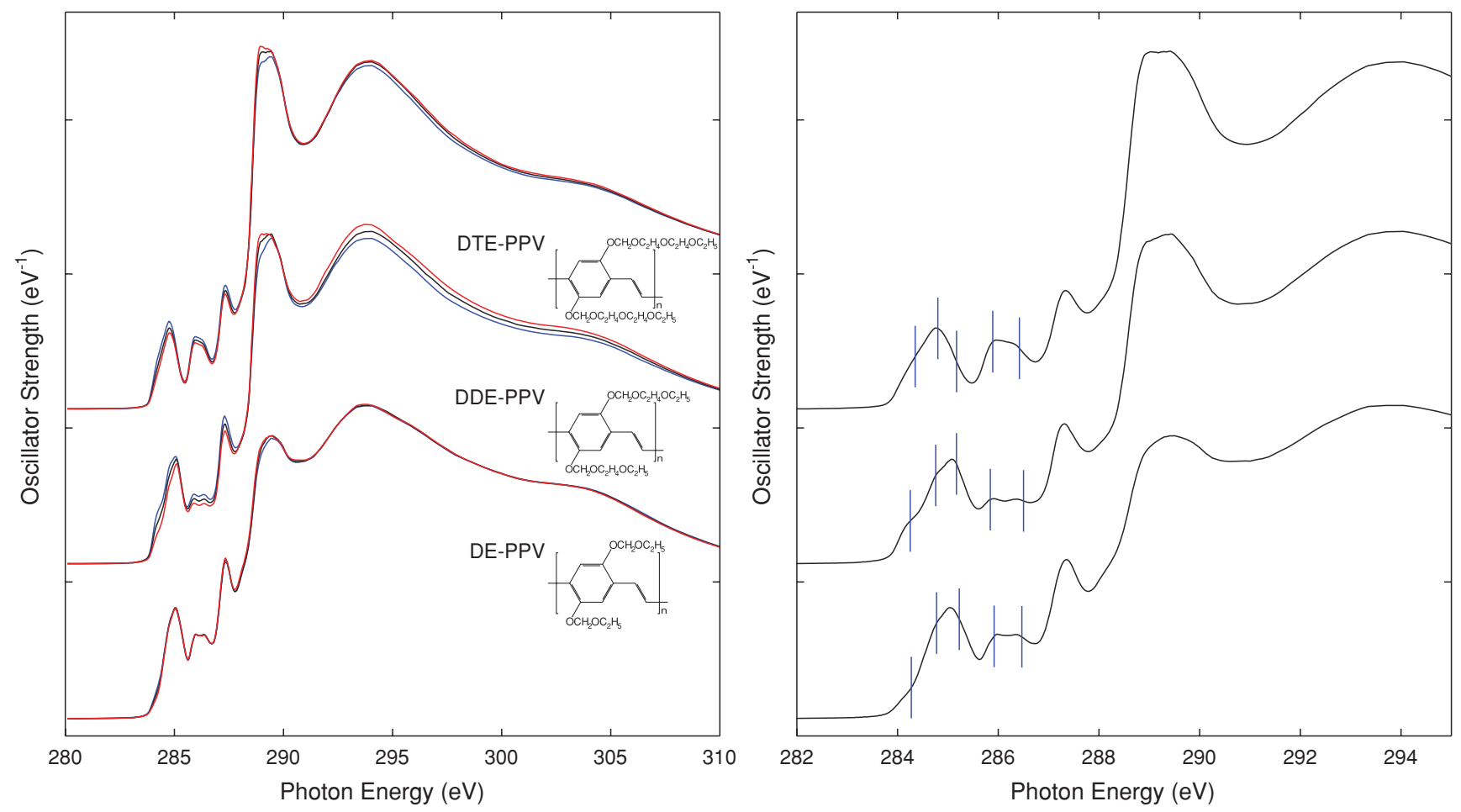

\begin{tabular}{cccc}
\hline \multicolumn{4}{c}{ Energy (eV) } \\
\hline$\#$ & DTE-PPV & DDE-PPV & DE-PPV \\
\hline 1 & 284.35 & 284.25 & 284.27 \\
2 & 284.80 & 284.76 & 284.78 \\
3 & 285.17 & 285.17 & 285.23 \\
4 & 285.89 & 285.84 & 285.92 \\
5 & 286.42 & 286.50 & 286.47 \\
\hline
\end{tabular}

FIG. 3. (left) C 1s NEXAFS spectra of DTE-PPV, DDE-PPV, and DE-PPV (labels for polymers refer to Table III) at $20^{\circ}$ (blue), $50^{\circ}$ (black), and $90^{\circ}$ (normal, red) $x$-ray incidence. (right) Expanded low energy regions of the same spectra with vertical lines marking the fitted resonance positions.

units, each with a solubilizing hexyl side chain. The P3HT spectrum demonstrates a clear set of split $\mathrm{C} 1 \mathrm{~s} \rightarrow \pi^{*}$ resonances near $285 \mathrm{eV}$ due to strong delocalization of the electronic structure along the conjugated backbone and the presence of the sulfur, strong $\mathrm{C} 1 \mathrm{~s}(\mathrm{C}-\mathrm{H}) \rightarrow \sigma_{\mathrm{C}-\mathrm{H}}^{*}$ resonances at approximately $287-288 \mathrm{eV}$, corresponding to the hexyl side chains, and a broad set of $\mathrm{C} 1 \mathrm{~s}(\mathrm{C}-\mathrm{C}) \rightarrow \sigma_{\mathrm{C}-\mathrm{C}}^{*}$ resonances near $293 \mathrm{eV}$. These spectral features, and their trends with varying alkyl side-chain length, have been previously described by Hitchcock et al. ${ }^{55}$ The PDQT spectrum displays the same spectral features, although the chemical structure is somewhat different from that of P3HT; while P3HT has a hexyl side chain on each thiophene group, PDQT has a dodecyl sidechain on every first and fourth thiophene unit and no side chain on every second and third thiophene unit. Therefore, P3HT and PDQT have identical elemental compositions but different structure, resulting in subtle spectral differences in all three types of resonances: first, the $\mathrm{C} 1 \mathrm{~s} \rightarrow \pi *$ resonances near $285 \mathrm{eV}$ show small differences in the splitting; second, the $\mathrm{C} 1 \mathrm{~s}(\mathrm{C}-\mathrm{H}) \rightarrow \sigma_{\mathrm{C}-\mathrm{H}}^{*}$ resonances near $287 \mathrm{eV}$ are less intense in the PDQT than in the P3HT spectrum; and third, the $\mathrm{C} 1 \mathrm{~s}(\mathrm{C}-\mathrm{C}) \rightarrow \sigma_{\mathrm{C}-\mathrm{C}}^{*}$ resonances near $293 \mathrm{eV}$ are broader in the PQDT spectrum than for P3HT. A more obvious difference can be observed between the P3HT and PMHT spectra, as shown in Fig. 5. The regioregular PMHT shows a single, strong $\mathrm{C} 1 \mathrm{~s} \rightarrow \pi^{*}$ resonance near $285.5 \mathrm{eV}$. In contrast, the $\mathrm{C} 1 \mathrm{~s} \rightarrow \pi^{*}$ resonances of P3HT near $285 \mathrm{eV}$ show a distinct splitting, such a radical spectral difference due to the presence or absence of a methyl group to the thiophene ring, which already includes a hexyl side chain, represents a very strong departure from the building block model. The methyl group seems to inhibit significant interaction along the backbone, possibly due to twisting of the backbone due to steric hindrance. It might also disrupt ordering in the material and the associated $\pi-\pi$ stacking.

Finally, Fig. 6 shows some other organic materials (as listed in Table V) commonly included in devices that utilize the conjugated polymer materials discussed here. The first group, shown in the upper half of Fig. 6 is PSS and two different formulations of the PEDOT emulsion in PSS that are often used as a planarization and electron blocking layer on the device ITO anode. These three spectra are almost identical (except for a small difference in the intensity of the $\mathrm{C} 1 \mathrm{~s} \rightarrow \pi^{*}$ resonance at $285 \mathrm{eV}$ ) because the TEY NEXAFS detection method used in this work is surface sensitive and the surface of the PEDOT:PSS samples is enriched with PSS. ${ }^{56}$ Furthermore, PSS is the majority component in these PEDOT:PSS emulsions. The second set of materials include the solubilized fullerene molecules PCBM- $\mathrm{C}_{61}$ and PCBM-C $\mathrm{C}_{71}$; the spectra of these two materials display a large 

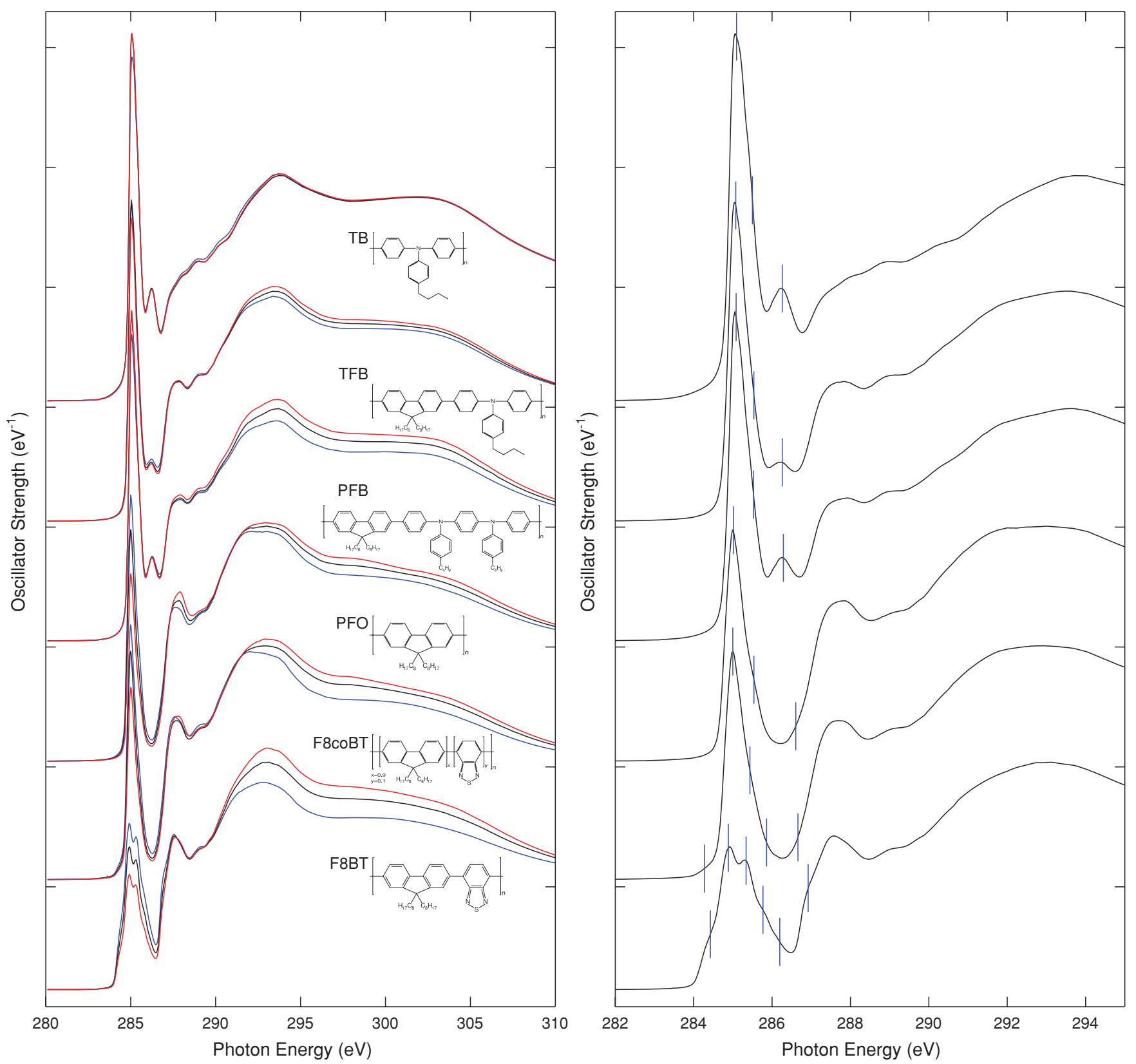

\begin{tabular}{ccccccc}
\hline \multicolumn{7}{c}{ Energy $(\mathrm{eV})$} \\
\hline$\#$ & TB & TFB & PFB & PFO & F8coBT & F8BT \\
\hline 1 & & & & & 284.27 & 284.43 \\
2 & 285.09 & 285.07 & 285.08 & 285.01 & 285.00 & 284.89 \\
3 & 285.50 & 285.54 & 285.53 & 285.54 & 285.44 & 285.34 \\
4 & & & & & 285.86 & 285.77 \\
5 & 286.26 & 286.26 & 286.29 & & & 286.20 \\
6 & & & & 286.61 & 286.66 & 286.92 \\
\hline
\end{tabular}

FIG. 4. (left) C 1s NEXAFS spectra of TB, TFB, PFB, PFO, F8-co-BT, and F8BT (labels for polymers refer to Table III) at $20^{\circ}$ (blue), $50^{\circ}$ (black), and $90^{\circ}$ (normal, red) x-ray incidence. (right) Expanded low energy regions of the same spectra with vertical lines marking the fitted resonance positions.

number of resonances that extend to higher energies than in most polymers. This is due to the extensive delocalization of the orbitals and the high local symmetry of the carbon atoms in these molecules. Interestingly, despite the high spectral resolution of these measurements, the TEY NEXAFS spectrum of PCBM-C ${ }_{61}$ shown in Fig. 6 displays a significantly weaker $\mathrm{C} 1 \mathrm{~s} \rightarrow \pi^{*}$ resonance near $284.5 \mathrm{eV}$ than is observed in NEXAFS spectra acquired by transmission measurements. ${ }^{11,18}$ While one would naturally challenge the resolution of the beamline upon observing such reduced resonance intensity, this argument is countered by the sharp and intense $\mathrm{C} 1 \mathrm{~s} \rightarrow \pi *$ resonance near $285 \mathrm{eV}$ in the PSS spectrum (also shown in Fig. 6), which was measured immediately after the PCBM spectra. Such difference in the PCBM-C ${ }_{61} \mathrm{C} 1 \mathrm{~s}$ 

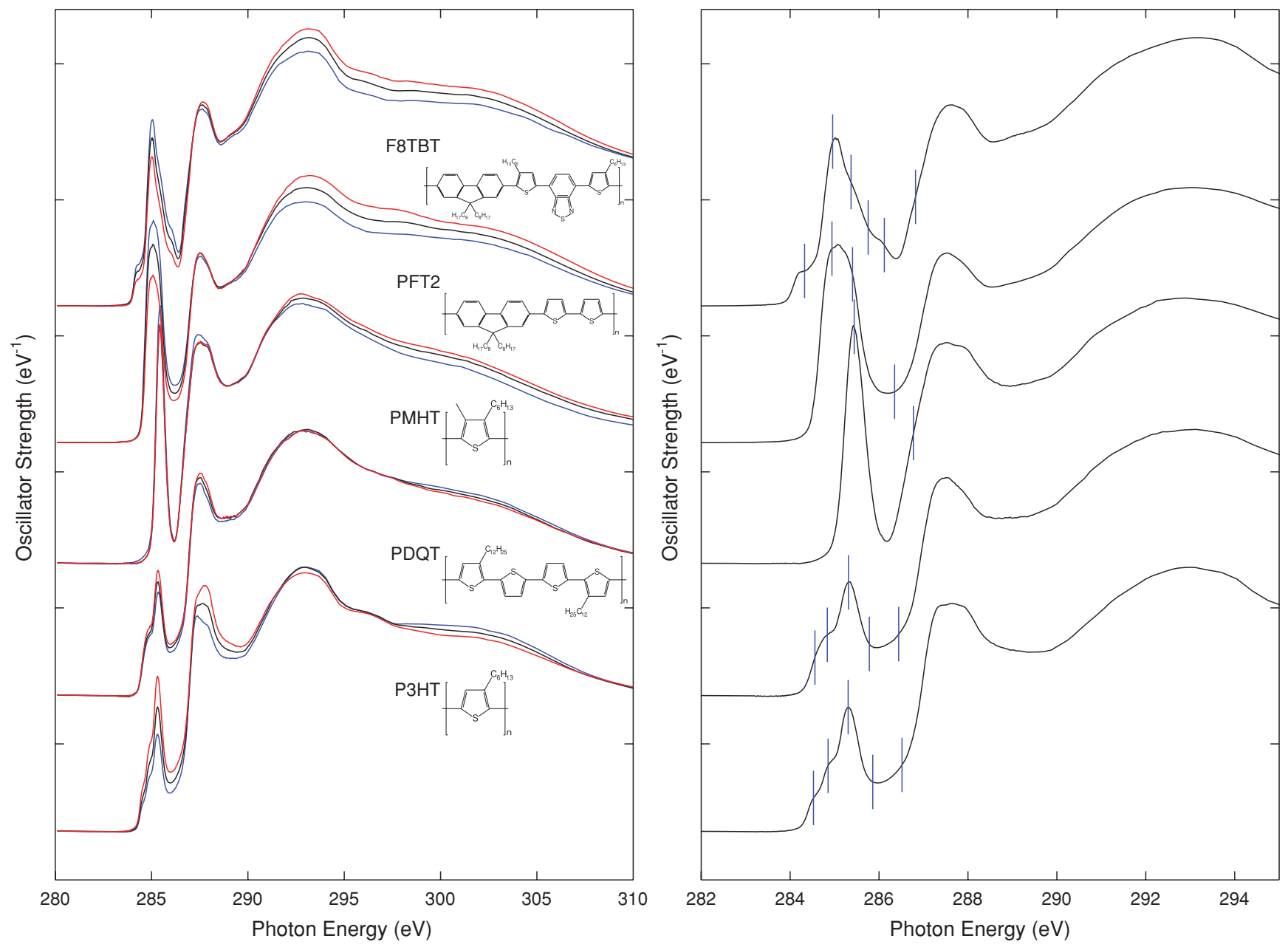

\begin{tabular}{cccccc}
\hline \multicolumn{5}{c}{ Energy (eV) } \\
\hline$\#$ & F8TBT & PFT2 & PMHT & PDQT & P3HT \\
\hline 1 & 284.33 & & & 284.56 & 284.53 \\
2 & 284.96 & 284.94 & & 284.84 & 284.85 \\
3 & 285.37 & 285.40 & 285.44 & 285.31 & 285.31 \\
4 & 285.76 & & & 285.78 & 285.86 \\
5 & 286.12 & & & & \\
6 & & 286.35 & & 286.44 & 286.52 \\
7 & 286.82 & & 286.77 & & \\
\hline
\end{tabular}

FIG. 5. (left) C 1s NEXAFS spectra of F8TBT, PFT2, PMHT, PDQT, and P3HT (labels for polymers refer to Table IV) at $20^{\circ}$ (blue), $50^{\circ}$ (black), and $90^{\circ}$ (normal, red) x-ray incidence. (right) Expanded low energy regions of the same spectra with vertical lines marking the fitted resonance positions. Note that the pre-edge intensity in these sulfur containing polymers is much higher than in most other materials, as can be readily seen by the large distance of the trace above the tick marks, which represent the zero for each spectrum.

$\rightarrow \pi^{*}$ resonance intensity must originate in some surface effect of the material and is visible via the different probe depths of TEY (surface) and transmission (bulk) mode NEXAFS experiments. It is likely that the same behaviour occurs with PCBM- $\mathrm{C}_{71}$ as well, although transmission NEXAFS data is currently not available to confirm it. Further experiments investigating the surface and bulk NEXAFS spectra of these materials are planned.

It is interesting to note that many of the materials whose spectra exhibit the broadest, low energy features have found considerable success in optoelectronic devices, notably the PPVs, ${ }^{57-63}$ F8BT $^{64-69}{ }^{\text {F8TBT }},{ }^{70-75}$ and P3HT. ${ }^{75-80}$ The corollary of deviation from the building block model is that splitting and broadening of NEXAFS resonances is a result of significant interaction between the chemical groups of the observed molecule. Since the interesting electrical properties of these materials are derived from the electronic delocalization along the conjugated backbone, it is reasonable to expect that greater interaction between the groups making up the polymer backbone leads to improved electronic properties (such as charge mobility) as well as stronger splitting and broadening of the NEXAFS resonances.

\section{CONCLUSIONS}

We have measured with high energy resolution the NEXAFS spectra of 23 semiconducting polymers plus some other organic materials that are frequently used in polymer 

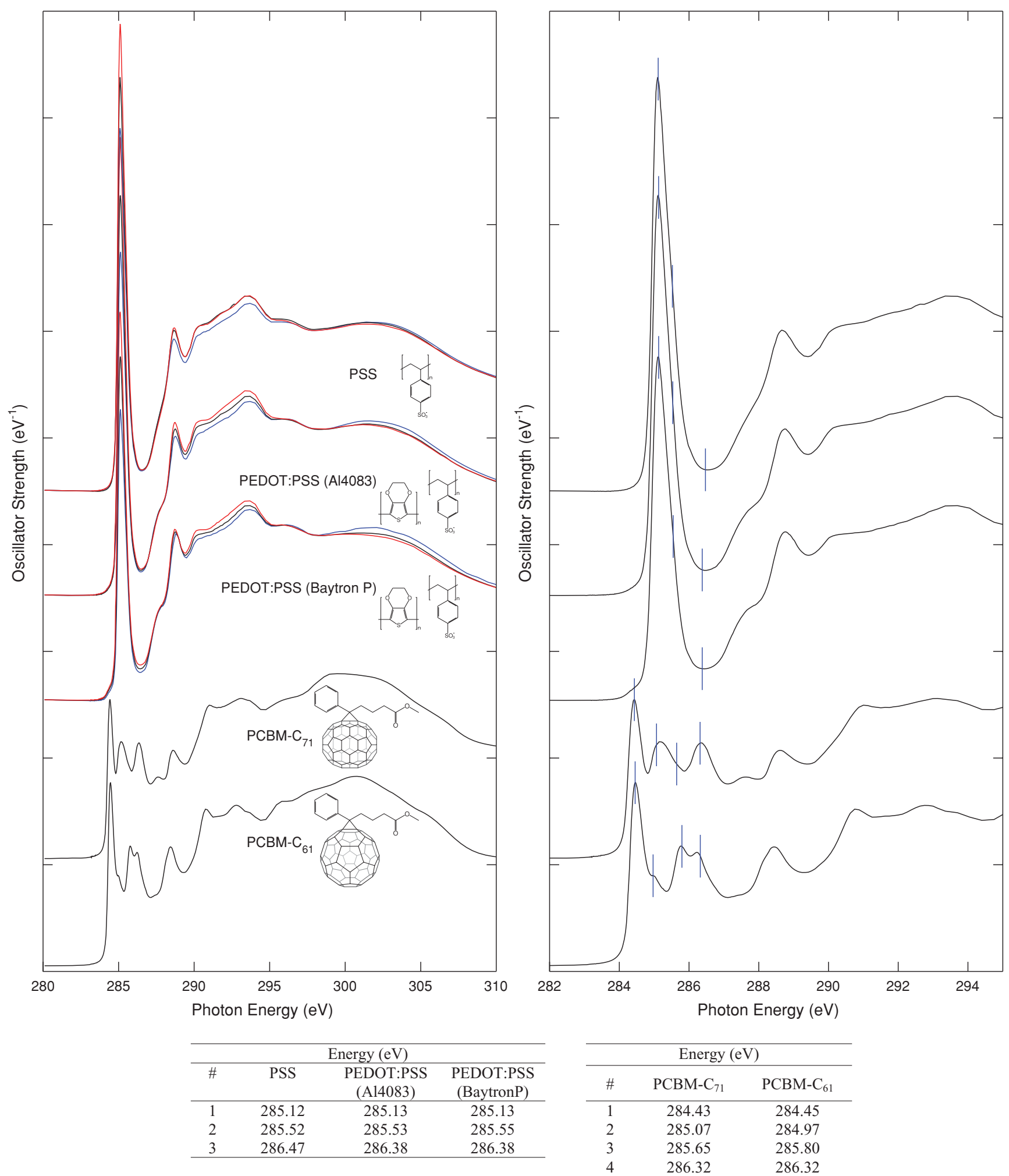

FIG. 6. (left) C 1s NEXAFS spectra of PSS, PEDOT:PSS, PCBM-C 71 , and PCBM-C 61 (labels for materials refer to Table V ) at $20^{\circ}$ (blue), $50^{\circ}$ (black), and $90^{\circ}$ (normal, red) x-ray incidence. (right) Expanded low energy regions of the same spectra with vertical lines marking the fitted resonance positions.

device research. These spectra have been carefully photon energy calibrated and are made available in a database as reference spectra. The width of the resonance features observed in these spectra is limited by the delocalized electronic structure of the materials. It is considered unlikely that finer spec- tral detail exists beyond that which is observed in this work. These reference spectra and the optical constants derived from them should facilitate analysis or organic devices with spectromicroscopy, resonant scattering, resonant reflectivity, or NEXAFS surface spectroscopy. 


\section{ACKNOWLEDGMENTS}

Work by NCSU was supported by the US Department of Energy, Office of Science, Basic Energy Science, Division of Materials Science and Engineering under Contract No. DE-FG02-98ER45737. Portions of this research were carried out at SSRL (BL 10-1), a national user facility operated by Stanford University on behalf of the US Department of Energy, Office of Basic Energy Science. The authors thank Cambridge Display Technology Ltd. for supply of PFB, F8BT, and F8TBT and also thank R. A. Segalman, Y. Tao, and the University of California, Berkeley, for supply of DEH-PPV, DEPPPV, DDDO-PPV, DOO-PPV, DBO-PPV, DTE-PPV, DDEPPV, and DE-PPV. The authors thank C. R. McNeill for useful discussions.

${ }^{1}$ J. Stöhr, NEXAFS Spectroscopy (Springer, Heidelberg, 1992).

${ }^{2}$ H. Ade and A. P. Hitchcock, Polymer 49, 643 (2008).

${ }^{3}$ O. Dhez, H. Ade, and S. Urquhart, J. Electron Spectrosc. Relat. Phenom. 128, 85 (2003)

${ }^{4}$ S. G. Urquhart and H. Ade, J. Phys. Chem. B 106, 8531 (2002).

${ }^{5}$ D. A. Outka, J. Stöhr, J. P. Rabe, and J. D. Swalen, J. Chem. Phys. 88, 4076 (1988).

${ }^{6}$ D. A. Outka, J. Stöhr, J. P. Rabe, J. D. Swalen, and H. H. Rotermund, Phys. Rev. Lett. 59, 1321 (1987).

${ }^{7}$ G. Hähner, M. Kinzler, C. Wöll, M. Grunze, M. K. Scheller, and L. S. Cederbaum, Phys. Rev. Lett. 67, 851 (1991).

${ }^{8}$ G. Hähner, M. Kinzler, C. Wöll, M. Grunze, M. K. Scheller, and L. S. Cederbaum, Phys. Rev. Lett. 69, 694 (1992).

${ }^{9}$ K. Kanai, T. Miyazaki, H. Suzuki, M. Inaba, Y. Ouchib, and K. Sekib, Phys. Chem. Chem. Phys. 12, 273 (2010).

${ }^{10}$ B. Watts and C. R. McNeill, Macromol. Rapid Commun. 31, 1706 (2010).

${ }^{11}$ B. Watts, W. J. Belcher, L. Thomsen, H. Ade, and P. C. Dastoor, Macromolecules 42, 8392 (2009).

${ }^{12}$ C. R. McNeill, B. Watts, L. Thomsen, W. J. Belcher, N. C. Greenham, P. C. Dastoor, and H. Ade, Macromolecules 42, 3347 (2009).

${ }^{13}$ K. B. Burke, W. J. Belcher, L. Thomsen, B. Watts, C. R. McNeill, H. Ade, and P. C. Dastoor, Macromolecules 42, 3098 (2009).

${ }^{14}$ C. R. McNeill, B. Watts, L. Thomsen, W. J. Belcher, S. Swaraj, H. Ade, and P. C. Dastoor, Nanotechnology 19, 424015 (2008).

${ }^{15}$ C. R. McNeill, B. Watts, L. Thomsen, H. Ade, N. C. Greenham, and P. C. Dastoor, Macromolecules 40, 3263 (2007).

${ }^{16}$ C. R. McNeill, B. Watts, L. Thomsen, W. J. Belcher, A. L. D. Kilcoyne, N. C. Greenham, and P. C. Dastoor, Small 2, 1432 (2006).

${ }^{17}$ C. R. McNeill, B. Watts, L. Thomsen, W. J. Belcher, N. C. Greenham, and P. C. Dastoor, Nano Lett. 6, 1202 (2006).

${ }^{18}$ B. A. Collins, L. Guignard, E. Gann, X. He, C. R. McNeil, and H. Ade, Appl. Phys. Chem. Lett. 1, 3160 (2010).

${ }^{19}$ G. E. Mitchell, B. G. Landes, J. Lyons, B. J. Kern, M. J. Devon, I. Koprinarov, E. M. Gullikson, and J. B. Kortright, Appl. Phys. Lett. 89, 044101 (2006)

${ }^{20}$ T. Araki, H. Ade, J. M. Stubbs, D. C. Sundberg, G. E. Mitchell, J. B. Kortright, and A. L. D. Kilcoyne, Appl. Phys. Lett. 89, 124106 (2006).

${ }^{21}$ J. M. Virgili, Y. F. Tao, J. B. Kortright, N. P. Balsara, and R. A. Segalman, Macromolecules 40, 2092 (2007).

${ }^{22}$ S. Swaraj, C. Wang, H. Yan, B. Watts, J. Lüning, C. R. McNeill, and H. Ade, Nano Lett. 10, 2863 (2010).

${ }^{23}$ C. Wang, A. Garcia, H. P. Yan, K. E. Sohn, A. Hexemer, T. Q. Nguyen, G. C. Bazan, E. J. Kramer, and H. Ade, Vac. Sci. Technol. A 131, 12538 (2009).

${ }^{24}$ C. Wang, T. Araki, B. Watts, S. Harton, T. Koga, S. Basu, and H. Ade, J. Vac. Sci. Technol. A 25, 575 (2007)

${ }^{25}$ C. Wang, T. Araki, and H. Ade, Appl. Phys. Lett. 87, 214109 (2005).

${ }^{26}$ H. Yan, S. Swaraj, C. Wang, I. Hwang, N. C. Greenham, C. Groves, H. Ade, and C. R. McNeill, Adv. Funct. Mater. 20, 4329 (2010).

${ }^{27}$ J. Kikuma and B. P. Tonner, J. Electron Spectrosc. Relat. Phenom. 82, 53 (1996).

${ }^{28}$ P. L. Cook, X. S. Liu, W. L. Yang, and F. J. Himpsel, J. Chem. Phys. 131, 194701 (2009).
${ }^{29}$ A. Hitchcock and D. Mancini, J. Electron Spectrosc. Relat. Phenom. 67, 1 (1994).

${ }^{30}$ M. Kim, H. Lee, B. Kim, J. Kim, and Y. Park, Phys. Scr. T115, 393 (2005).

${ }^{31}$ Y. Jung, T. Y. Cho, D. Y. Yoon, C. W. Frank, and J. Lüning, Macromolecules 38, 867 (2005).

${ }^{32}$ L. R. Pattison, A. Hexemer, E. J. Kramer, S. Krishnan, P. M. Petroff, and D. A. Fischer, Macromolecules 39, 2225 (2006).

${ }^{33}$ J. Park, R. Yang, C. V. Hoven, A. Garcia, D. A. Fischer, T.-Q. Nguyen, G. C. Bazan, and D. M. DeLongchamp, Adv. Mater. 20, 2491 (2008).

${ }^{34}$ P. K.-H. Ho, L.-L. Chua, M. Dipankar, X. Gao, D. Qi, A. T.-S. Wee, J.-F. Chang, and R. H. Friend, Adv. Mater. 19, 215 (2007).

${ }^{35}$ D. W. Lee, K. Kima, J.-I. Jin, and Y. Park, Synth. Met. 143, 181 (2004).

${ }^{36}$ D. S. Chung, S. J. Lee, J. W. Park, D. B. Choi, D. H. Lee, J. W. Park, S. C. Shin, Y.-H. Kim, S.-K. Kwon, and C. E. Park, Chem. Mater. 20, 3450 (2008).

${ }^{37}$ Q. Yuan, S. C. B. Mannsfeld, M. L. Tang, M. Roberts, M. F. Toney, D. M. DeLongchamp, and Z. Bao, Chem. Mater. 20, 2763 (2008).

${ }^{38}$ M. C. Gurau, D. M. Delongchamp, B. M. Vogel, E. K. Lin, D. A. Fischer, S. Sambasivan, and L. J. Richter, Langmuir 23, 834 (2007).

${ }^{39}$ D. S. Germack, C. K. Chan, B. H. Hamadani, L. J. Richter, D. A. Fischer, D. J. Gundlach, and D. M. DeLongchamp, Appl. Phys. Lett. 94, 233303 (2009).

${ }^{40}$ I. McCulloch, M. Heeney, M. L. Chabinyc, D. DeLongchamp, R. J. Kline, M. Cölle, W. Duffy, D. Fischer, D. Gundlach, B. Hamadani, R. Hamilton, L. Richter, A. Salleo, M. Shkunov, D. Sparrowe, S. Tierney, and W. Zhang, Adv. Mater. 21, 1091 (2009).

${ }^{41}$ R. J. Kline, D. M. DeLongchamp, D. A. Fischer, E. K. Lin, L. J. Richter, M. L. Chabinyc, M. F. Toney, M. Heeney, and I. McCulloch, Macromolecules 40, 7960 (2007).

${ }^{42}$ Y.-S. Yoon, H. Kang, B. G. Kim, and J.-C. Lee, Macromol. Chem. Phys. 211, 353 (2010).

${ }^{43}$ H. Cheun, X. Liu, F. J. Himpsel, M. Knaapila, U. Scherf, M. Torkkeli, and M. J. Winokur, Macromolecules 41, 6463 (2008).

${ }^{44}$ B. Watts, L. Thomsen, and P. C. Dastoor, J. Electron Spectrosc. Relat. Phenom. 151, 105 (2006).

${ }^{45}$ B. Watts and H. Ade, J. Electron Spectrosc. Relat. Phenom. 162, 49 (2008).

${ }^{46}$ J. C. Scott, J. H. Kaufman, P. J. Brock, R. DiPietro, J. Salem, and J. A. Goitia, J. Appl. Phys. 79, 2745 (1996).

${ }^{47}$ B. L. Henke, E. M. Gullikson, and J. C. Davis, At. Data Nucl. Data Tables 54(2), 181 (1993).

${ }^{48}$ Updated tables from Ref. 46 are also available from the internet. URL http://www.cxro.lbl.gov

${ }^{49}$ P. Bruzzoni, R. M. Carranza, J. R. Collet Lacoste, and E. A. Crespo, Electrochim. Acta 48, 341 (2002).

${ }^{50}$ D. T. Cromer and D. Liberman, J. Chem. Phys. 53, 1891 (1970).

${ }^{51}$ Y. Zou, T. Araki, G. Appel, A. L. D. Kilcoyne, and H. Ade, Chem. Phys. Lett. 430, 287 (2006).

${ }^{52}$ A. Schöll, R. Fink, E. Umbach, G. E. Mitchell, S. G. Urquhart, and H. Ade, Chem. Phys. Lett. 370, 834 (2003).

${ }^{53}$ S. G. Urquhart, H. Ade, M. Rafailovich, J. S. Sokolov, and Y. Zhang, Chem. Phys. Lett. 322, 412 (2000).

${ }^{54}$ S. G. Urquhart, A. P. Smith, H. W. Ade, A. P. Hitchcock, E. G. Rightor, and W. Lidy, J. Phys. Chem. B 103, 4603 (1999).

${ }^{55}$ A. P. Hitchcock, G. Tourillon, R. Garrett, G. P. Williams, C. Mahatsekake, and C. Andrieu, J. Phys. Chem. 94, 2327 (1990).

${ }^{56}$ G. Greczynskia, Th. Kuglerb, M. Keila, W. Osikowicza, M. Fahlmanc, and W. R. Salanecka, J. Electron Spectrosc. Relat. Phenom. 121, 1 (2001)

${ }^{57}$ J. H. Burroughes, D. D. C. Bradley, A. R. Brown, R. N. Marks, K. Mackay, R. H. Friend, P. L. Burns, and A. B. Holmes, Nature 347, 539 (1990).

${ }^{58}$ D. Braun and A. J. Heeger, Appl. Phys. Lett. 58, 1982 (1991).

${ }^{59}$ H. Becker, H. Spreitzer, W. Kreuder, E. Kluge, H. Schenk, I. Parker, and Y. Cao, Adv. Mater. 12, 42 (2000).

${ }^{60}$ S. E. Shaheen, C. J. Brabec, N. S. Sariciftci, F. Padinger, T. Fromherz, and J. C. Hummelen, Appl. Phys. Lett. 78, 841 (2001).

${ }^{61}$ S. C. Veenstra, W. J. H. Verhees, J. M. Kroon, M. M. Koetse, J. Sweelssen, J. J. A. M. Bastiaansen, H. F. M. Schoo, X. Yang, A. Alexeev, J. Loos, U. S. Schubert, and M. M. Wienk, Chem. Mater. 16, 2503 (2004).

${ }^{62}$ L.-L. Chua, J. Zaumseil, J. F. Chang, E. C.-W. Ou, P. K.-H. Ho, H. Sirringhaus, and R. H. Friend, Nature 434, 194 (2005).

${ }^{63}$ T. Sakanoue, E. Fujiwara, R. Yamada, and H. Tada, Appl. Phys. Lett. 84, 3037 (2004). 
${ }^{64}$ J. J. M. Halls, A. C. Arias, J. D. MacKenzie, W. Wu, M. Inbasekaran, E. P. Woo, and R. H. Friend, Adv. Mater. 12, 498 (2000).

${ }^{65}$ Y. Kim, S. Cook, S. A. Choulis, J. Nelson, J. R. Durrant, and D. D. C. Bradley, Chem. Mater. 16, 4812 (2004).

${ }^{66}$ C. L. Donley, J. Zaumseil, J. W. Andreasen, M. M. Nielsen, H. Sirringhaus, R. H. Friend, and J. S. Kim, J. Am. Chem. Soc. 127, 12890 (2005).

${ }^{67}$ J. Zaumseil, C. L. Donley, J.-S. Kim, R. H. Friend, and H. Sirringhaus, Adv. Mater. 18, 2708 (2006).

${ }^{68}$ D. Kabra, M. H. Song, B. Wenger, R. H. Friend, and H. J. Snaith, Adv. Mater 20, 3447 (2008)

${ }^{69}$ J. S. Kim, P. K. H. Ho, C. E. Murphy, and R. H. Friend, Macromolecules 37, 2861 (2004)

${ }^{70}$ C. Shi, Y. Yao, Y. Yang, and Q. Pei, J. Am. Chem. Soc. 128, 8980 (2006).

${ }^{71}$ O. Inganäs, M. Svensson, F. Zhang, A. Gadisa, N. K. Persson, X. Wang, and M. R. Andersson, Appl. Phys. A 79, 31 (2004).

${ }^{72}$ L. H. Slooff, S. C. Veenstra, J. M. Kroon, D. J. D. Moet, J. Sweelssen, and M. M. Koetse, Appl. Phys. Lett. 90, 143506 (2007).
${ }^{73}$ Q. Hou, Y. Xu, W. Yang, M. Yuan, J. Peng, and Y. Cao, J. Mater. Chem. 12, 2887 (2002).

${ }^{74}$ M. Inbasekaran, E. P. Woo, W. S. Wu, and M. T. Bernius, World Patent 00/46321A1 (2000)

${ }^{75}$ C. R. McNeill, A. Abrusci, J. Zaumseil, R. Wilson, M. J. McKiernan, J. J. M. Halls, N. C. Greenham, and R. H. Friend, Appl. Phys. Lett. 90, 193506 (2007).

${ }^{76}$ H. Sirringhaus, T. Kawase, R. H. Friend, T. Shimoda, M. Inbasekaran, W. Wu, and E. P. Woo, Science 290, 2123 (2000).

${ }^{77}$ W. Ma, C. Yang, X. Gong, K. Lee, and A. J. Heeger, Adv. Funct. Mater. 15, 1617 (2005).

${ }^{78}$ M. A. Green, K. Emery, Y. Hishikawa, and W. Warta, Prog. Photovoltaics 16, 61 (2008).

${ }^{79}$ G. Dennler, M. C. Scharber, and C. J. Brabec, Adv. Mater. 21, 1 (2009).

${ }^{80}$ M. Reyes-Reyes, K. Kim, and D. L. Carroll, Appl. Phys. Lett. 87, 083506 (2005). 